\title{
Sludge Formation Analysis in Hydraulic Oil of Load Haul Dumper 811MK V Machine Running at Elevated Temperatures for Bioenergy Applications
}

\author{
MohdAhteshamHussain Siddiqui, ${ }^{1,2}$ Sandeep K Pal, ${ }^{1}$ Nagesh Dewangan, ${ }^{3}$ \\ Somnath Chattopadhyaya, ${ }^{1}$ Shubham Sharma (D), ${ }^{4}$ Saeed Nekoonam (D, ${ }^{5}$ \\ and Alibek Issakhov ${ }^{6}$ \\ ${ }^{1}$ Indian Institute of Technology (Indian School of Mines), Dhanbad, India \\ ${ }^{2}$ Coal India Limited, Western Coal Fields Limited, Saoner, Nagpur, India \\ ${ }^{3}$ Indian Institute of Technology, Kharagpur, India \\ ${ }^{4}$ Department of Mechanical Engg., IK Gujral Punjab Technical University, Main Campus, Kapurthala 144603, India \\ ${ }^{5}$ Department of Renewable Energies and Environment, Faculty of New Sciences and Technologies, University of Tehran, \\ Tehran, Iran \\ ${ }^{6}$ Faculty of Mechanics and Mathematics, Department of Mathematical and Computer Modelling, \\ Al-Farabi Kazakh National University, Almaty, Kazakhstan
}

Correspondence should be addressed to Shubham Sharma; shubham543sharma@gmail.com and Saeed Nekoonam; saeednekoonam@gmail.com

Received 27 April 2021; Accepted 2 June 2021; Published 24 June 2021

Academic Editor: Alireza Baghban

Copyright (C) 2021 MohdAhteshamHussain Siddiqui et al. This is an open access article distributed under the Creative Commons Attribution License, which permits unrestricted use, distribution, and reproduction in any medium, provided the original work is properly cited.

\begin{abstract}
Hydraulic oil degrades expediently during operating at elevated temperatures, and due to oil degradation, malfunction of all hydraulic components starts that hampers the hydraulic functioning of the machine. An inefficient component of the hydraulic system converts useful energy into heat. Overheating starts when the rate of heat energy escaping from the system overcomes the rate of heat dissipation. Viscosity, total acidic number (TAN), rheology, and FTIR analyses were carried out on the oil samples collected chronically, and the reasons for degradation and sludge formation were evaluated; the results showed that thermal cracking resistance capacity of the oil was low due to the imbalance percentage of additives in the base oil. Sludge impaired the system efficiency and prejudicially creates repercussions on power consumption. Sludge can be recycled for biofuel and to avoid imbalance in the ecosystem. The test result is plotted in a 3D view graph using the MATLAB R 2019 software for a better explanation. Variation in the behaviour of the hydraulic fluid with respect to time, temperature, shear stress, and shear rate was studied, and the result is validated with correlation and regression analyses.
\end{abstract}

\section{Introduction}

LHD $811 \mathrm{MK}$ V is a DGMS-approved electrohydraulically operated machine used in underground mines for loading coal from coal faces, hauling, and discharging coal at the discharge point. The volume of the push plate bucket is $1.5 \mathrm{~m}^{3}$, and it can haul 1.5 tons of coal. LHD can move up to the range of 100 meters in either direction. It is attached with a flexible, five-core, $25 \mathrm{~mm}^{2}$, and 100 -meter trailing cable.

Hydraulic fluids are the primary sufferers due to overheating. In this article, critical analyses were performed on chemical changes that occurred at elevated temperatures in a particular batch of hydraulic fluids, which affected the physical performance of the hydraulic components of the LHD. Hydraulic oil is used for not only transmitting power 
in hydrostatic control systems in the form of flow and pressure but also lubricating the contact surfaces, flushing out heat, and cleaning the system. Oil samples were collected chronologically from the machine, under different time periods of running where particular batch fluids had been utilized in machines. Continuous running at elevated temperatures leads to oil degradation as a consequence of thermal cracking and oxidation. Polymerisation causes problems in the flow of oil into small cross-section pipes and hydraulic components of the hydraulic system. Internal scaling and choking can defunct the components' performances. Tribology of hydraulic fluids are drastically affected by thermal degradation, and overall performance of the machine is affected considerably. Overheating is the most disconcerting problem encountered in hydrostatic transmission. Temperature is inversely proportional to the viscosity of the oil [1]. If the viscosity of the oil goes beyond the limits of the recommended range (i.e., TOW), the performance of hydraulic components is drastically affected. If the viscosity of the operating oil goes beyond higher or lower limits of TOW, power loss occurs due to fluid friction or mechanical friction with internal leakages, respectively. The onset of a vicious circle which expeditiously inducts the heat load while mitigating the use of full power and repercussion indicates a rise in the temperature. Heat generation cycle continues till the machine is in operation. Viscosity curtails the oil lubricating property; hence, oil film cannot be developed between the mating parts inevitably and the system instinctively behaves erratically [2]. Lack of lubrication accelerates wear-and-tear rates, and consequently, catastrophic failure of the system occurs [3].

A rise in the temperature of hydraulic oil shows that inefficient components are there in the hydraulic system that generates heat. Maximum recommended temperature of the oil in underground coal mines is $82^{\circ} \mathrm{C}$. Hydraulic oil is the carrier of heat. The state of the oil easily indicates a machine's health condition. The polymerization of hydraulic oil is caused by thermal degradation due to continuous running at elevated temperatures [4]. A semisolid varnish-like substance develops in the oil which converts into sludge, as shown in Figure 1 [5]. This is an insoluble and sticky material, which forms a layer on the internal surfaces of the hydraulic components. This unwanted insoluble compound and polymer are impairing prejudicial results on the performance of hydraulic components. Sludge is poisonous in nature and enhances corrosion rates due to acidic compounds [6] and thus causes malfunctioning of valves, confined space blocking, and orifice clogging, as shown Figure 2. Sabotage of pump flow (the cooling capacity of the heat exchanger is pared by scaling due to varnish depositing on the internal surface) increases the friction resistance and wear rates, but equipment overall efficiency is reduced. Sludge cannot be removed from the internal parts of the hydraulic apparatus or system. Atypical changes in viscosity breach the performance of additives added in the base oil for improving its functional properties [7] and at last defunct the complete hydraulic system. Ageing and thermal degradation of hydraulic oil can be

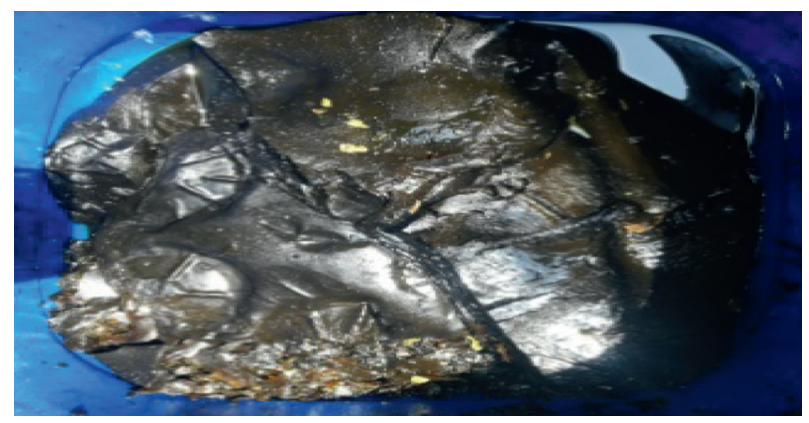

FIgURE 1: Sludge deposited in the oil tank of LHD.

ascertained expeditiously by measuring incongruity in terms of viscosity and change in colour right from amber to brown and to black with putrid or sour odour.

The substantive measure is either to avoid the formation of toxic sludge or to convert this harmful waste into fuels by the prevalent befitting processes before indulging in the ecosystem [8]. Biofuels can be generated from pollutant sludge with deconstructing by anaerobic digestion, combustion, pyrolysis, and gasification $[9,10]$. It mitigates the viability of imbalance of nature due to toxic pollutants [11-13].

Fire-resistant hydraulic fluid HFDU-68, Viscosity Grade VG-68, 240 litres, is used in the LHD working underground coal mines where fire risk is more. It is a synthetic fluid made up of organic ester having a viscosity index of 175 and kinematic viscosity between 61.2 and 74.8cSt @ 400, conforming to specification as per IS-10532, Part-5 organic ester type and IS: 7895-1975 (reaffirmed 2002) mentioned in Table 1. Four oil samples were taken from the machine in the chronological order starting from new oil to 250-hour, 500hour, and 750-hour used oil for the analysis. The OEM recommends replacing the hydraulic oil with new oil at every $1000 \mathrm{hrs}$ of running.

Hnilicova et al. [14] performed a study on the tribotechnical diagnostic method for monitoring the conditions of the hydraulic oil used in the handling line Baljer and Zembrod machine. Five samples were taken during the one year of period. Viscosity, total acid number (TAN), and FTIR analyses were carried out on the oil. They diagnosed that hydraulic fluids that are recommended by the manufacturers are suitable for machine operation in the given environment. Heredia-Cancino et al. [15] studied the effects of elevated temperature degradation of engine oil on tribological performance. This paper used different approach to study gear oil deterioration by combining depleted oil with fresh oil in order to know consumption per unit time. Deteriorated gear oils were studied in IR spectroscopy analysis by authors. A rheometer was used to assess the dynamic viscosity at different temperature ranges, and the tribological efficiency was measured by using a tribometer under various temperatures for simulated gear oil. Results showed that replicate oil degradation actually happened, and the friction coefficient is decreased at high temperatures. Kalligers [16] examined the fatigue of the hydraulic engine of the elevator via its hydraulic oil analysis. Seven samples of hydraulic oil of three elevators were taken for corrosion-and-wear analysis. The rate 


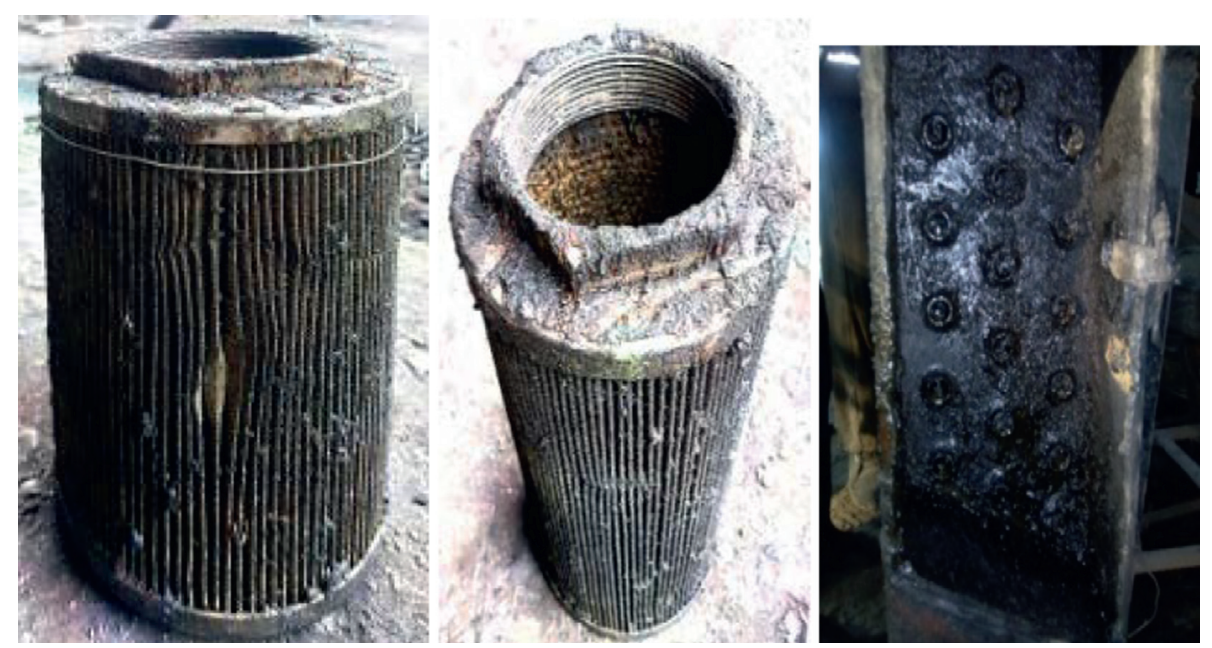

FIGURE 2: Suction strainer and radiator choked by sludge.

TABle 1: Test report of new hydraulic oil HFDU-68 done at Testing Laboratory of M/s Sun Oil Company Pvt. Ltd., Kolkata.

\begin{tabular}{|c|c|c|c|c|}
\hline $\begin{array}{l}\text { S. } \\
\text { No. }\end{array}$ & Test parameters & $\begin{array}{l}\text { Test method IS } \\
1448 / \text { ASTM }\end{array}$ & Results & $\begin{array}{l}\text { Specification IS-10532, Part-5, organic ester type and IS: 7895- } \\
1975 \text { (reaffirmed 2002) for fire-resistance properties }\end{array}$ \\
\hline 1 & Appearance & Qualitative & Pale yellow & Pale yellow \\
\hline 2 & Type & Qualitative & $\begin{array}{l}\text { Synthetic fluids } \\
\text { (organic ester) }\end{array}$ & Synthetic fluids (organic ester) \\
\hline \multirow[t]{2}{*}{3} & $\begin{array}{c}\text { Kinematic Viscosity@ } \\
40^{\circ} \mathrm{C}, \mathrm{cSt}\end{array}$ & IS $1448[\mathrm{P}: 25]$ & 68.69 & $61.2-74.8$ \\
\hline & $\begin{array}{c}\text { Kinematic viscosity@ } \\
100^{\circ} \mathrm{C}, \mathrm{cSt}\end{array}$ & IS $1448[\mathrm{P}: 25]$ & 11.9 & $11-13$ \\
\hline 4 & Viscosity index & IS $1448[\mathrm{P}: 56]$ & 176 & 175 \\
\hline 5 & $\begin{array}{l}\text { Specific gravity } \\
\quad @ 15^{\circ} \mathrm{C}\end{array}$ & IS $1448[\mathrm{P}: 32]$ & 0.9006 & $0.90-0.99$ \\
\hline 6 & $\begin{array}{c}\text { Flash point, } \mathrm{COC},{ }^{\circ} \mathrm{C} \text {, } \\
\min \end{array}$ & IS $1448[\mathrm{P}: 69]$ & 288 & 250 \\
\hline 7 & Fire point, ${ }^{\circ} \mathrm{C}$, min & IS $1448[\mathrm{P}: 69]$ & 306 & 290 \\
\hline 8 & Pour point, ${ }^{\circ} \mathrm{C}, \max$ & IS $1448[\mathrm{P}: 10]$ & $(-) 12$ & $(-) 9$ \\
\hline 9 & TAN, mg KOH/g & & 1.1 & - \\
\hline
\end{tabular}

of oxidation and phosphorus, zinc, chlorine, and calcium were evaluated to know the erosion percentage of lift. Seven samples of oil from each lift were collected. And it was concluded that the standard of hydraulic oil is not appropriate up to the specification of manufacturers and probably dangerous for the machine. Wolak [17] studied the changes in lubricating properties with TAN analysis of synthetic oil in accordance with ASTMD664. Five engine oils of different manufacturers with the same SAE were taken. Statistica-10 software was used for the analysis of data collected in three measurements. Twenty-five cars were tested to check the change in TAN with respect to kilometre travelled and to know the trend of degradation with time and kilometre travelled. Zzeyania et al. [18] performed the electron paramagnetic resonance (EPR) and infrared Fourier transform (FTIR) analyses on synthetic lubricating oil of dieselpowered motor vehicle engines and assessed the degradation rates. Degradation of the oil is the cause of the cluster of free radicals in the lubricant. FTIR capacity demonstrates the fracturing of the hydrocarbon base oil lubricant and the presence of rust materials. FTIR spectroscopy is also a useful method for identifying molecules of base lubricating oil and additives resulting from degradation. Taborda et al. [19] developed a model for studying the effects of nanoparticles on the rheological behaviour of heavy and extra heavy crude oil. They used two types of mathematical models, that is, Herschel-Bulky and modified $\mathrm{Pal}$ and Rhodes for the rheology of pseudoplastic and suspensions substance, respectively. Viscosity in the presence of nanoparticles with respect to volume fraction and shear rate was calculated. Flow behaviour and consistency index parameters affecting the viscosity were also determined. Singh et al. [20] studied how to prevent hydraulic system failure by monitoring its contamination rates. An effective and timely contamination management system, by monitoring temperature, viscosity, and contamination level, can save the system. Research has been carried out on a motor vehicle hydraulically controlled device used for the expression of weighty goods after the stage has been levelled with outrigger cylinders. It has been eminent that due to careful control and monitoring of the level of contamination, there is a substantial improvement in reliability, operating economy, and long repair life. Stanciu [21] described the rheological behaviour of five types of rapeseed oils with mathematical models. Dynamic viscosity with respect to 
shear rate from 3 to $1312 \mathrm{~S}^{-1}$ and temperature from $40^{\circ} \mathrm{C}$ to $90^{\circ} \mathrm{C}$ were studied with a Haake VT 550 viscometer. The trend of decreasing log dynamic viscosity with respect to the log shear rate of the proposed oil having characteristics of non-Newtonian pseudoplastic fluid and correlation coefficient of the mathematical model is also close to unity. Xu et al. [22] studied the influence of lubricating oil additives on the oxidation of particulate matter of diesel oil with thermogravimetric analysis and found that fuel of high cetane number reacts faster. Yao et al. [23] evaluated that the high temperature is the prime reason for aero lubricating oil degradation. The polymerization of oil takes place at high temperature, and sludge is formed due to the thermal cracking of lower molecular compound. Ji et al. [24] analyzed the rheological properties of vegetable oil asphalt with an improved method, which is an indicator at a wider range, as compared with the conventional methods. The rheological method is more reliable than the conventional method.

Thermal degradation analysis of fire-resistant hydraulic oil HFDU-68 was done first time on the samples collected chronically from the machine itself with four types of test. Experimental data were examined using the correlation and regression analyses for validation of tests. The block diagram of the research methodology is shown in Figure 3.

\section{Analytical Analysis}

Correlation analysis shows the relationship between variables and their mutual bonding within the analysis [25].

\subsection{Karl Pearson's Correlation Coefficient}

$$
r=\frac{\sum_{i=1}^{n}\left(X_{i}-\bar{X}\right)\left(Y_{i}-\bar{Y}\right)}{\sqrt{\sum_{i=1}^{n}\left(X_{i}-\bar{X}\right)^{2} \sum_{i=1}^{n}\left(Y_{i}-\bar{Y}\right)^{2}}} .
$$

Regression analysis shows the dependency of one variable to the other variables and also how the dependent variable is affected by a change in the independent variables. It is also a tool for forecasting the behaviour of the dependent variable.

\subsection{Least Square Method of Regression Analysis}

$$
\begin{aligned}
& b=\frac{\sum X Y-n \cdot \bar{X} \cdot Y}{\sum X^{2}-n \cdot \bar{X}^{2}}, \\
& r=\frac{b \sqrt{\sum X^{2}-n \cdot \bar{X}^{2}}}{\sqrt{\sum Y^{2}-n \cdot \bar{Y}^{2}}}, \\
& a=\bar{Y}-b \bar{X},
\end{aligned}
$$

where $\bar{X}$ and $\bar{Y}$ are the mean value of $X$ and $Y$, and

$$
Y=a+b X
$$

where $Y$ is the dependent variable and $X$ is the independent variable.

\section{Experimental Study}

3.1. Viscosity Test. A Stabinger viscometer SVM30 shown in Figure 4 was used to measure kinematic viscosity, dynamic viscosity, and fluid density with respect to temperature variations. Stabinger viscometer setup was cleaned by toluene, and after that, 10 milliliters of oil from a sample was taken in the syringe and filled in the port. Temperature of the viscometer was set at the desired point on which reading could be taken. The machine runs for a few minutes for the testing, and the measured value can be seen on the monitor. This procedure is applied to all four oil samples:Figure 5 for new oil, Figure 6 for $250 \mathrm{hrs}$, Figure 7 for $500 \mathrm{hrs}$, and Figure 8 for $750 \mathrm{hrs}$, collected from the machine itself. After each test, the setup must be cleaned and cooled for the next sample.

There are several equations available that illustrate the relation between temperature and viscosity since 1886 , from Reynolds equation to 1974 Manning equation [26]. VTF equation (Vogel, Tammann, and Fulcher) is the most appropriate for comparing the relationship between the behaviour of viscosity under different temperature ranges and measures the deviation of reading concerning the standards [27].

$$
\mu=a e^{b /(T-C)} .
$$

where $\mu=$ dynamic viscosity (Pa-s), $T_{A}=$ absolute temperature (K), $a=0.5, b=496, c=213 . a, b$, and $c$ are constants of VTF.

For the analysis of viscosity variation with temperature, the test has been done on a Stabinger viscometer. The analysis is done in the temperature range of $30^{\circ} \mathrm{C}$ to $90^{\circ} \mathrm{C}$ at an interval of $10^{\circ} \mathrm{C}$. The change in dynamic viscosity, kinematic viscosity, and density with respect to temperature changes are recorded and plotted, as shown in Figures 9-11, respectively. It is observed that, at $30^{\circ} \mathrm{C}$, all the four samples have the highest viscosity and the viscosity decreases exponentially with temperature. It is instinctive that viscosity is affected by temperature and working hours. Temperature is inversely proportional to the viscosity, although working hours is directly affecting the viscosity. The machine running at elevated temperature reduced the oil viscosity, but the cynosure is with initial viscosity reading ascending with duration. High temperature acts as a momentous catalyst, which augments the degradation reaction. The rate of oxidation is the epitome for the repercussion of high-temperature operation.

Changes in viscosity, varnish deposition on the internal surfaces of hydraulic apparatus, and finally formation of sludge occur, which interdict the hydraulic operation expeditiously. It is evident that varnish deposition and sludge formation are the pertinent indicators for hydraulic oil worsening.

Table 2 shows experimental readings of oil samples. Furthermore, correlation and regression analyses were done on the test result of oil for speculating entity behind its degradation and ascertain temperature and running hours' mutual roles apparently and are provided in Table 3 [28]. 


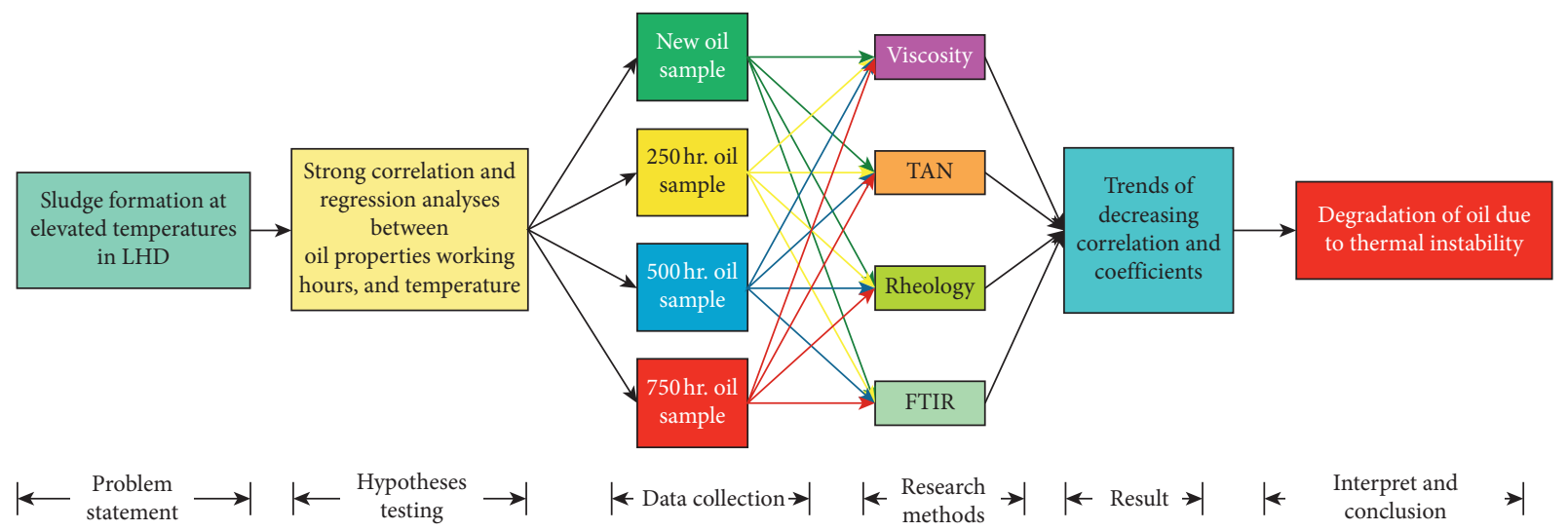

Figure 3: Block diagram of research methodology.

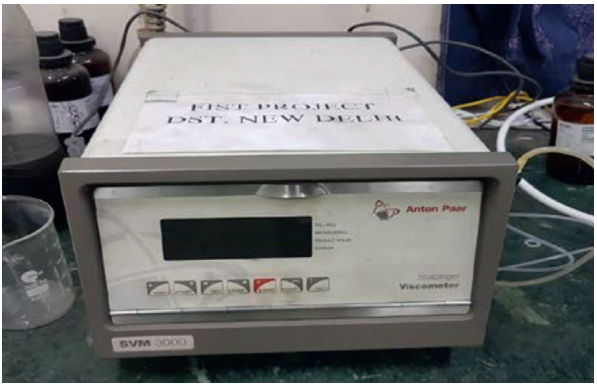

Figure 4: Experimental setup of Stabinger viscometer SVM30.

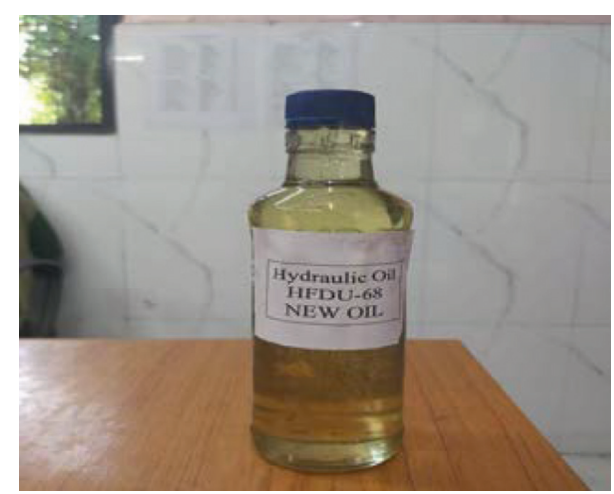

Figure 5: New oil sample.

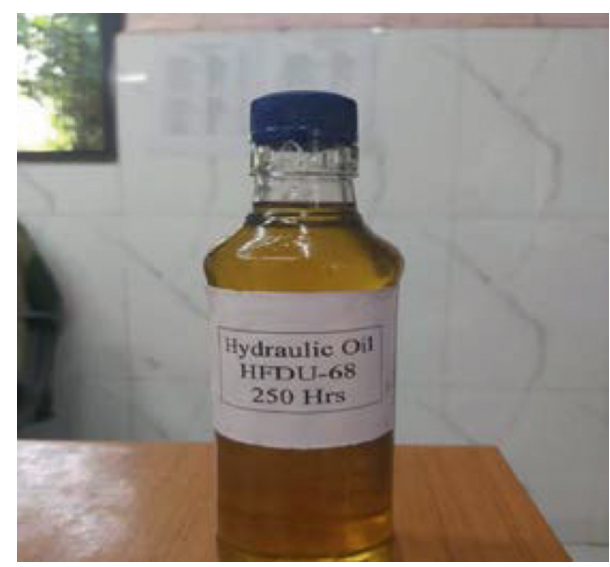

FIgURE 6: 250-hour used oil sample.

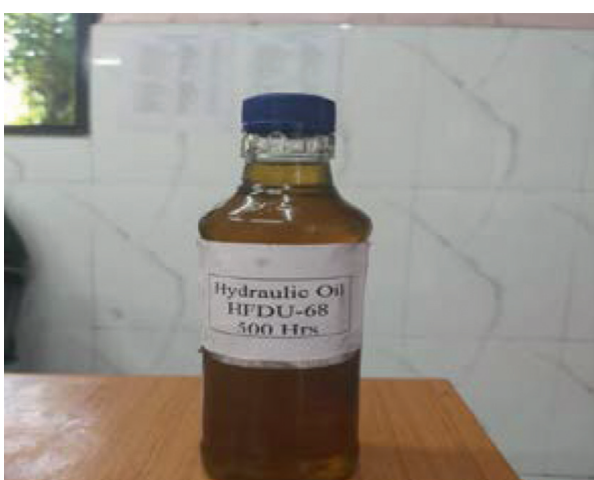

FIGURE 7: 500-hour used oil sample.

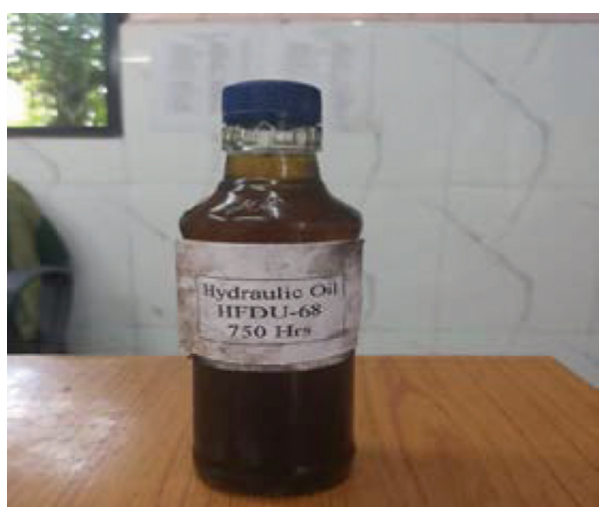

FIGURE 8: 750-hour used oil sample.

3.2. TAN Test. This test measures the concentration of acid in the oil. Quantity of potassium hydroxide is required for neutralizing the acid inside the oil sample, and measuring the weight, in milligram $\mathrm{KOH}$ per gram of oil $[29,30]$. It measures oxidation stability at elevated temperature (Figure 12).

This test was conducted at Anacon Laboratories Pvt. Ltd., Nagpur, according to the standard IS 1448 Part 106. The empty oxidation test tube is filled with a known volume of the oil sample to the graduation mark and slide over the inlet of the oxygen delivery tube. Then, the condenser is placed over the 


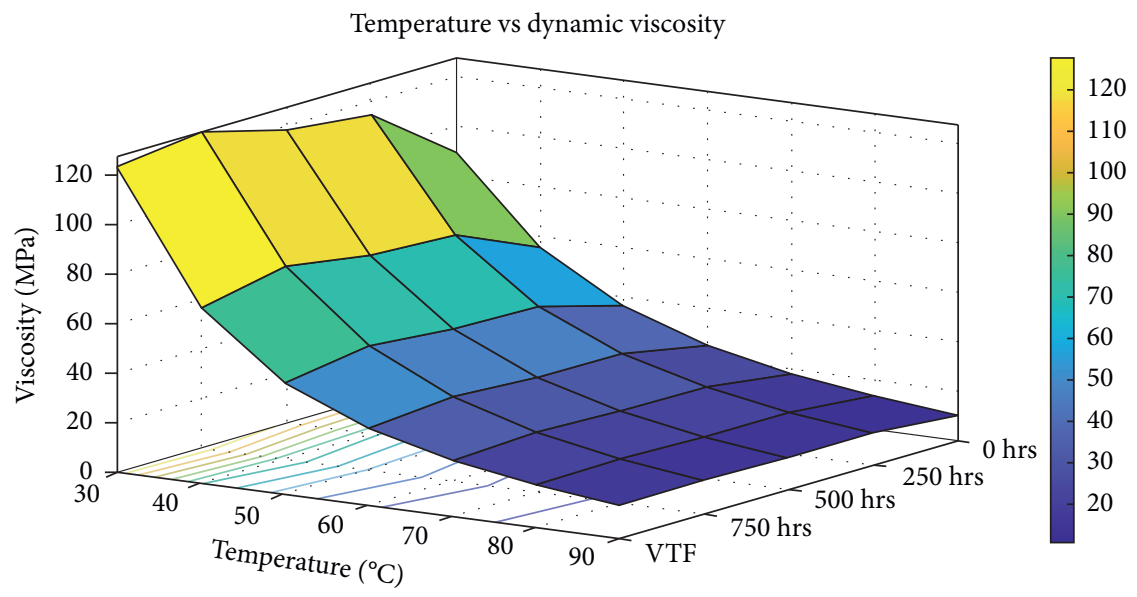

Figure 9: Change in dynamic viscosity with respect to temperature.

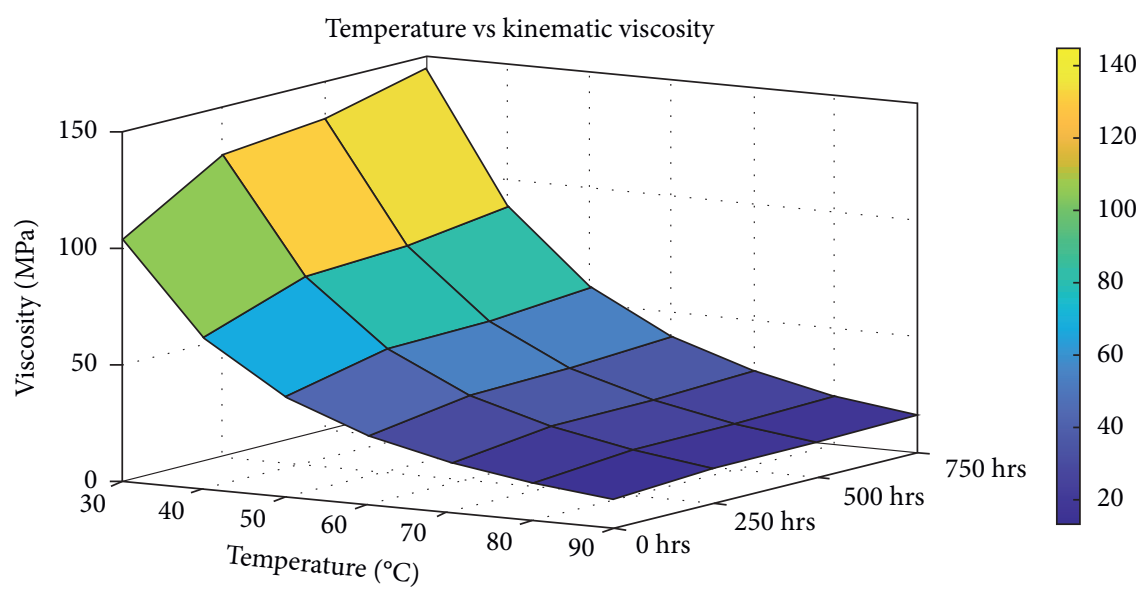

FIgURE 10: Change in kinematic viscosity with respect to temperature.

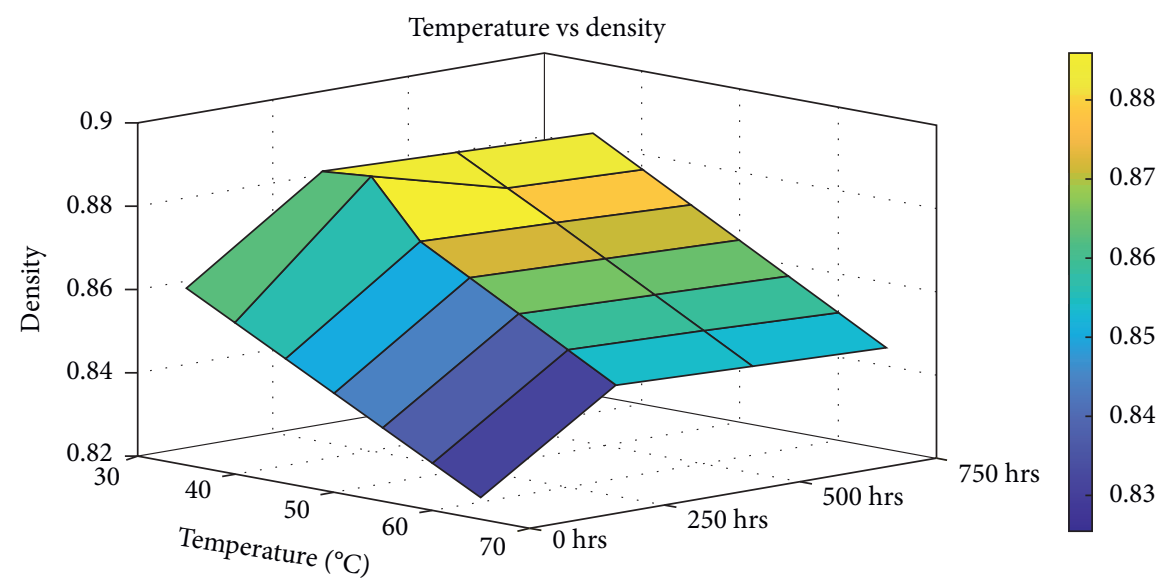

FIGURE 11: Change in density with respect to temperature.

oxygen delivery tube and test tube. The test tube is immersed in the heating bath. The heating bath liquid level is adjusted so that the tube is immersed in the liquid. The temperature of the outlet water should not exceed $32^{\circ} \mathrm{C}$ at any time during the test. The oxygen delivery tube is connected to the oxygen supply through the flow meter. And throughout the test, the temperature of the oil-water mixture (sample temperature) is maintained at $800^{\circ} \mathrm{C} \pm 1$ in a test cell with oxygen flowing. A known volume of 
TABLE 2: Experimental readings of oil samples.

\begin{tabular}{|c|c|c|c|c|c|c|c|c|c|c|c|c|}
\hline \multirow{2}{*}{ Temperature } & \multicolumn{4}{|c|}{ Dynamic viscosity } & \multicolumn{4}{|c|}{ Kinematic viscosity } & \multicolumn{4}{|c|}{ Density } \\
\hline & New & 250 & 500 & 750 & New & 250 & 500 & 750 & New & 250 & 500 & 750 \\
\hline 30 & 89.508 & 114.81 & 118.55 & 127.73 & 103.79 & 129.73 & 134.12 & 144.67 & 0.8624 & 0.885 & 0.8839 & 0.8829 \\
\hline 40 & 55.471 & 70.601 & 72.315 & 77.685 & 64.787 & 80.353 & 82.4 & 88.629 & 0.8562 & 0.886 & 0.8776 & 0.8765 \\
\hline 50 & 36.377 & 45.987 & 46.817 & 50.145 & 42.799 & 52.722 & 53.735 & 57.631 & 0.8499 & 0.8723 & 0.8713 & 0.8701 \\
\hline 60 & 25.033 & 31.424 & 31.885 & 34.053 & 29.67 & 36.295 & 36.866 & 39.428 & 0.8437 & 0.8658 & 0.8649 & 0.8637 \\
\hline 70 & 18.012 & 22.463 & 22.684 & 24.164 & 21.508 & 26.141 & 26.424 & 28.187 & 0.8374 & 0.8593 & 0.8585 & 0.8573 \\
\hline 80 & 13.415 & 16.646 & 16.775 & 17.792 & 16.139 & 19.518 & 19.663 & 20.912 & 0.8312 & 0.8529 & 0.8521 & 0.8508 \\
\hline 90 & 10.31 & 12.704 & 12.782 & 13.499 & 12.494 & 15.005 & 15.112 & 15.985 & 0.8252 & 0.8467 & 0.8458 & 0.8445 \\
\hline
\end{tabular}

TABLE 3: Correlation and regression chart of experimental values of viscosity with respect to temperature.

\begin{tabular}{lccr}
\hline Sample & Correlation coefficient of temperature and viscosity & \multicolumn{2}{c}{ Regression coefficient } \\
& & $R^{2}$ & Standard deviation \\
\hline 0 & --0.92243352 & 0.8508836 & 12.03187197 \\
250 & -0.92095639 & 0.84816066 & 15.65370721 \\
500 & -0.9191173 & 0.84477661 & 16.39375789 \\
750 & -0.91868327 & 0.84397895 & 17.74968999 \\
VTF & -0.90188825 & 0.81340242 & 18.64085751 \\
\hline
\end{tabular}

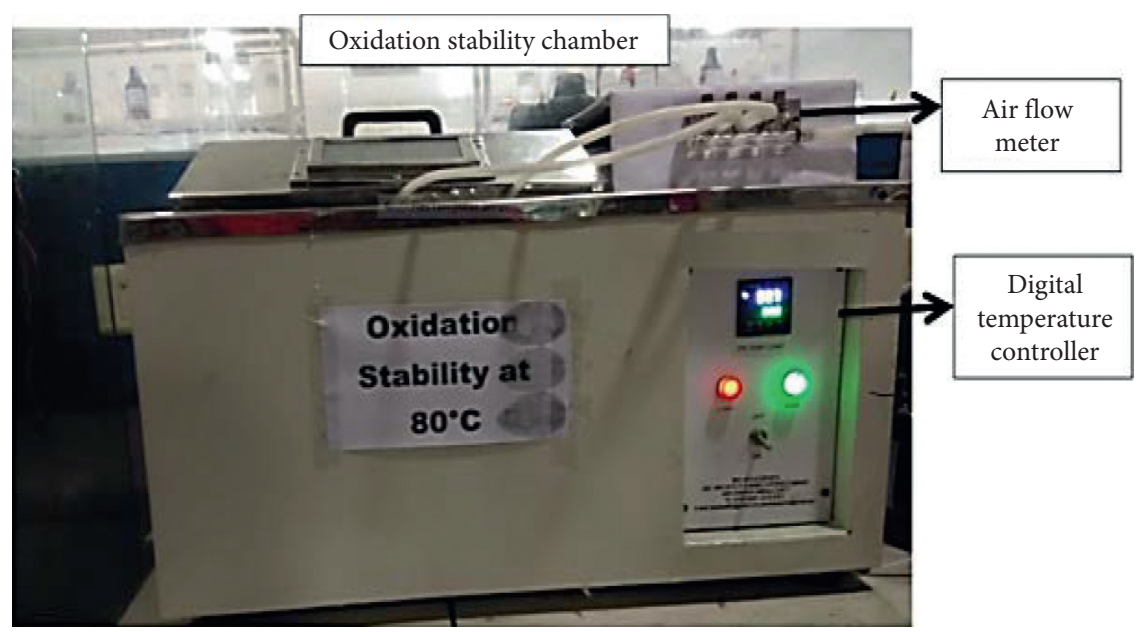

FIGURE 12: Oxidation stability chamber.

sample is dispensed into a sample vial for acid number analysis. The test oil sample should be shaken thoroughly before taking a sample from the vial for titration.

Depletion of antioxidants occurs in the oxidation process of oil. The total acid number increased due to the running time and operation at elevated temperature (Figure 13). The viscosity of oil increased due to more percentage of acid molecules and affects the functional stabilities of oil. Higher TAN indicates the prone to corrosion, varnish layering, and formation of sludge. It also reveals clogging of valves and filters, scaling on heat dissipation surface, due to varnish deposit which results in temperature and consequently oxidation rate increase (Table 4). Chart of correlation and regression analyses on the experiment values is shown in Table 5 .

$$
\mathrm{TAN}=\frac{\left(V_{t}-V_{\mathrm{bt}}\right) \times C_{\mathrm{koh}} \times 56.1}{M_{s}},
$$

where $V_{t}$ is the volume of the titrant added at the end point $(\mathrm{ml}), V_{\mathrm{bt}}$ is the volume of the titrant added at the end point of the blank titration ( $\mathrm{ml}), C_{\mathrm{koh}}$ is the concentration of $\mathrm{KOH}$ in 2-propanol titrant $(\mathrm{N})$, and $M_{s}$ is the mass of the sample analyzed (g).

3.3. Rheology Test. Shear flow and extensional flow are the types of behaviours encountered in fluid flow mechanism. Rotational rheometer focused on shear flow viscosity concerning shear rate $(0.01$ to $10001 / \mathrm{sec})$ at different temperatures [31]. The ratio of shear stress to shear rate is termed as 


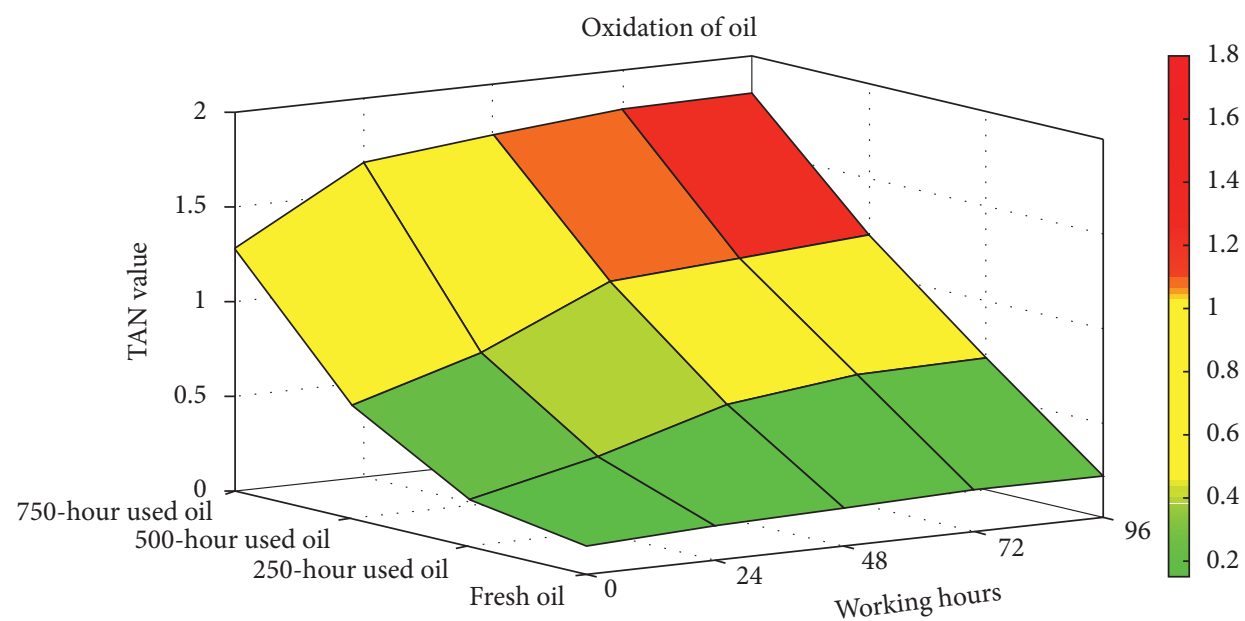

Figure 13: Oxidation curve of HFDU68 oil.

TABLE 4: Experimental readings of TAN.

\begin{tabular}{lccccc}
\hline Sample (hrs) & 0 & 24 & 48 & 72 & 96 \\
\hline New oil & 0.15 & 0.18 & 0.2 & 0.22 & 0.22 \\
250 & 0.25 & 0.4 & 0.6 & 0.68 & 0.7 \\
500 & 0.6 & 0.8 & 1.1 & 1.15 & 1.2 \\
750 & 1.28 & 1.66 & 1.73 & 1.79 & 1.8 \\
\hline
\end{tabular}

TABLE 5: Correlation and regression analyses between TAN and working hours of oil.

\begin{tabular}{lccc}
\hline Sample & Correlation coefficient & $R$ square & Standard deviation \\
\hline 0 & 0.9594 & 0.9205 & 0.0096 \\
250 & 0.9586 & 0.9189 & 0.064 \\
500 & 0.9468 & 0.8964 & 0.0962 \\
750 & 0.8591 & 0.738 & 0.1273 \\
\hline
\end{tabular}

dynamic viscosity, which accounts for the fluid friction between the layer and energy losses. The shear strain that occurs in the molecules of oil is measured by a rheometer (Model No.-AR 2000) and is tested as per ASTM D4440. To keep a minimum distance between the bearing and surface, the air compressor is maintained at a pressure of three bars in the rheometer. A cup-and-bob type geometric measuring device is used to measure liquid samples for Newtonian and non-Newtonian behaviour. A $50 \mathrm{ml}$ quantity of each sample was taken. This oil sample is kept in the geometry/measurement system, the testing temperature is set in the temperature controller, placed at the bottom of the geometry, and the test was carried out. The experimental setup is shown in Figure 14. The experiment was performed in the temperature range of $40^{\circ} \mathrm{C}$ to $80^{\circ} \mathrm{C}$ because the operating temperature is mainly near $60^{\circ} \mathrm{C}$. Dynamic viscosity and shear stress plot against shear rate vary between 0.01 and 1000 1/sec at different temperatures: Figure 15 shows for 40 degree centigrade, Figure 16 for 60 degree centigrade, and Figure 17 for 80 degree centigrade, respectively. A combined graph of viscosity, temperature, and shear rate is shown in Figure 18 and that of shear rate vs shear stress in Figure 19. A total of fifty readings were taken in 150 seconds for each sample at every specified temperature. Shear stress is equal to the torque multiplied by measuring system factor in the software. Torque is set in the machine according to the types of sample; high torque is used for a viscous sample and vice versa.

The power law or Ostwald-de Waele model for rheological behaviour analysis of oil is described as follows [32]:

$$
\eta(\gamma)=K \gamma^{n-1},
$$

taking $\log$ on both sides

$$
\log (\eta)=\log (k)+(n-1) \cdot \log (\gamma),
$$

where intercept $=\log (k)$, slope $=(n-1), n<1$ means shear thinning or pseudo plastic fluid, $n=1$ means newtonian fluid, and $n>1$ means shear thickening or dilatants' fluid. $k$ and $n$ are fluid consistency coefficient and power law index, respectively.

Correlation and regression analyses between the experimental values with shear stress in the ordinate and shear rate in the abscissa is shown in Table 6 and with viscosity in the ordinate and shear rate in the abscissa is shown in Table 7.

In the rheology test graph, the dynamic viscosity and shear rate are obtained. First, the graphs of all oil samples at different temperatures are obtained and then they are combined and the results are compared. In the viscosity versus shear rate graph, it was found that, at $40^{\circ} \mathrm{C}$, the viscosity decreases with the shear rate at around $60^{\circ} \mathrm{C}$ and increases with the shear rate at $80^{\circ} \mathrm{C}$. This means that if the temperature rises above $60^{\circ} \mathrm{C}$, viscosity increases with shear rate due to oxidation in hydraulic oil (Table 7).

3.4. Fourier Transform Infrared (FTIR) Spectroscopy. Fourier transform infrared spectroscopy is a powerful method used to detect oil pollution, by-products of oil degradation, and additives applied to oil to enhance oils' properties [33, 34]. This experiment was conducted to determine the functional group in the compound (Figure 20). The sample was under radiation of mid Infrared with a frequency of light waves from 4000 to 


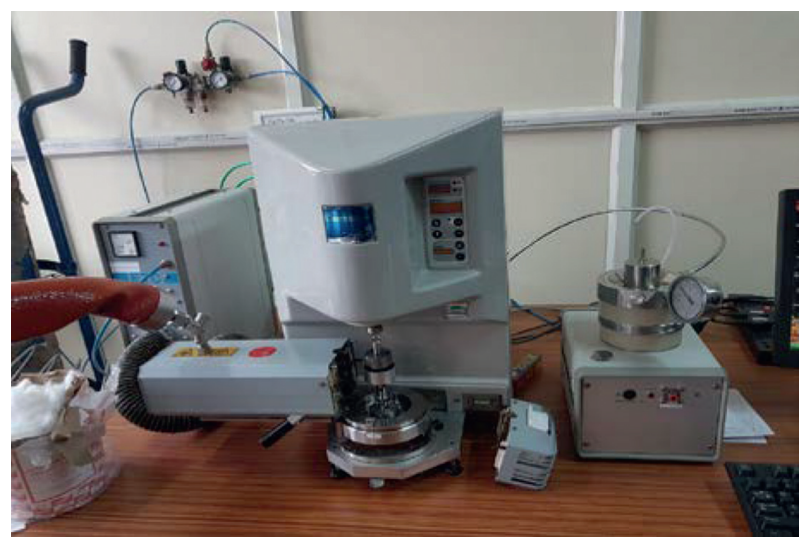

FIgURE 14: Air bearing rheometer.

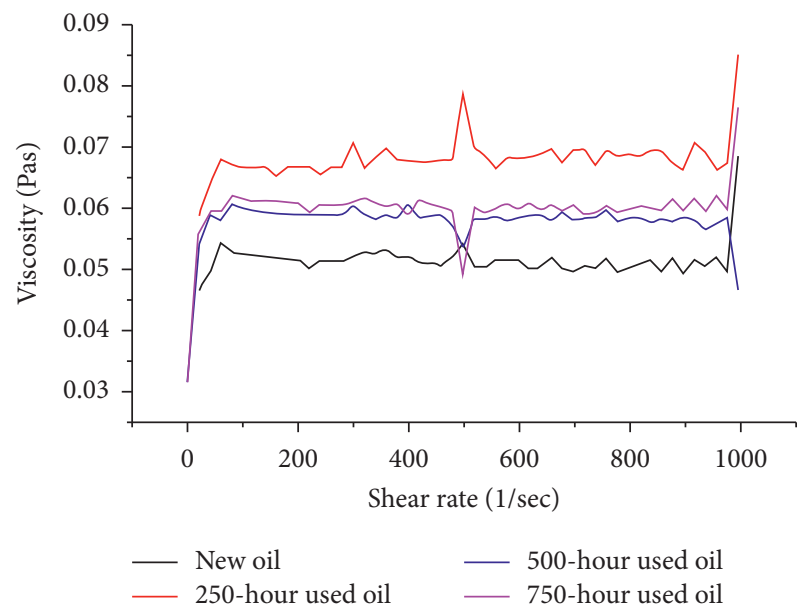

FIGURE 15: A combined graph of change in viscosity with shear rate at $40^{\circ} \mathrm{C}$.

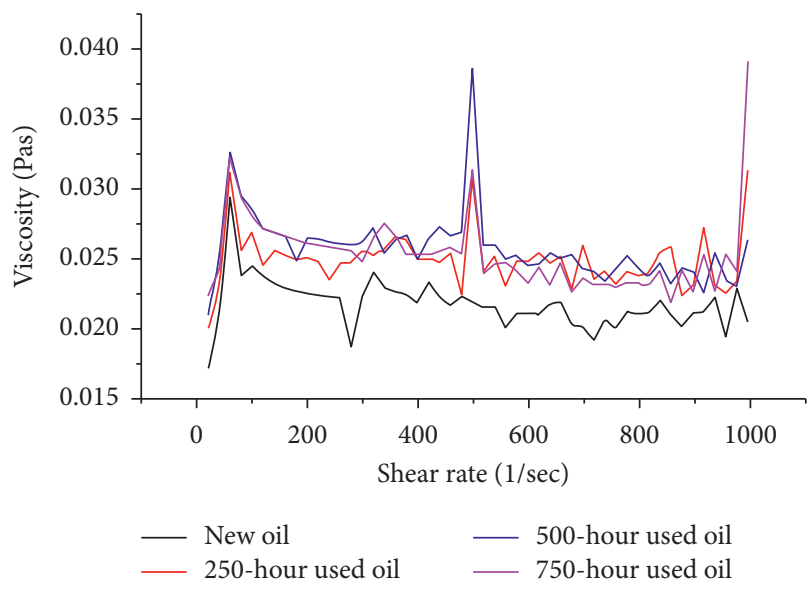

FIGURE 16: A combined graph of change in viscosity with shear rate at $60^{\circ} \mathrm{C}$.

$400 \mathrm{~cm}^{-1}$ ). Its molecules absorb light waves of only specific frequency, which cause stretching $\left(4000-1600 \mathrm{~cm}^{-1}\right)$ and bending (1600-400 $\left.\mathrm{cm}^{-1}\right)$ vibrations. Remaining transmitted light waves through the sample were detected in a detector and made spectrum accordingly [35]. The shape and intensity of the

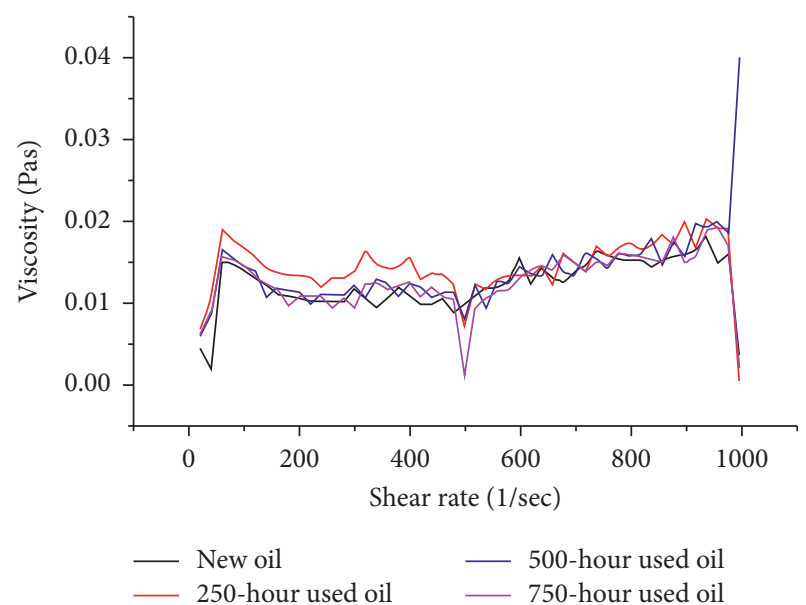

FIGURE 17: A combined graph of change in viscosity with shear rate at $80^{\circ} \mathrm{C}$.

peaks is used to identify the functional group molecules. Dipole moment and polarity define the intensity of peaks.

In infrared spectroscopy, the bond between atoms is considered as a spring and stretching or bending movement which governs according to Hooke's law.

\subsubsection{Stretching Frequency (W)}

$$
W=\frac{1}{2 \pi c}\left(f \frac{M c+M h}{M c M h}\right) .
$$

Wave number is inversely proportional to the mass of molecules and directly proportional to the bond strength.

In the range between 4000 and $3500 \mathrm{~cm}^{-1}$, the alcohol $(-\mathrm{OH})$ groups show decreased transmittance; hence, there is an increase in the quantity of $-\mathrm{OH}$ groups in oil. In the range between 3200 and $2800 \mathrm{~cm}^{-1}$, carboxylic acid $(-\mathrm{COOH})$ and alkane (-C-C-) groups are increased. These indicate braking of bonds and oxidation of additives. In the range between 2600 and $2200 \mathrm{~cm}^{-1}$, the aldehyde group is found, and it is increasing. In the range between 1800 and $1400 \mathrm{~cm}^{-1}$, carboxylic acid and amides are found. In the range between 1400 and $1000 \mathrm{~cm}^{-1}$, sulphonates, sulphides, sulfonic acid, sulphates, and esters have shown a decrease in transmittance (Figure 21).

The Beer-Lambert law states that absorption is proportional to the solute concentration (Table 8).

$$
A=\varepsilon P C,
$$

where $A=$ absorbance, $\varepsilon=$ molar absorptivity $\left(\mathrm{Lmol}^{-1} \mathrm{~cm}^{-1}\right)$, $P=$ path length of the cuvette containing the sample $(\mathrm{cm})$, and $C=$ concentration of the compound in the solution ( $\mathrm{mol}$ $\left.\mathrm{L}^{-1}\right)$.

$$
A=\log _{10}\left(\frac{100}{T[\%]}\right)=2-\log T[\%] .
$$

Region A: single-bonded molecules, e.g., O-H, C-H, and $\mathrm{N}-\mathrm{H}$, lie between wave number 2500 and $4000 \mathrm{~cm}^{-1}$ It is a 


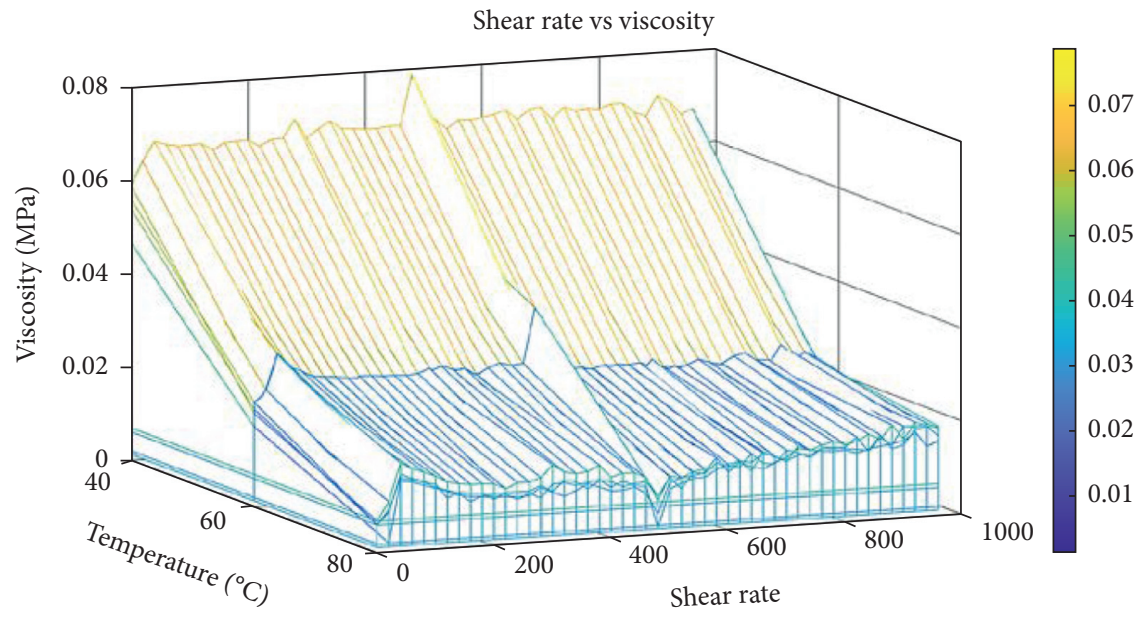

FIgURe 18: Plot of viscosity to shear rate.

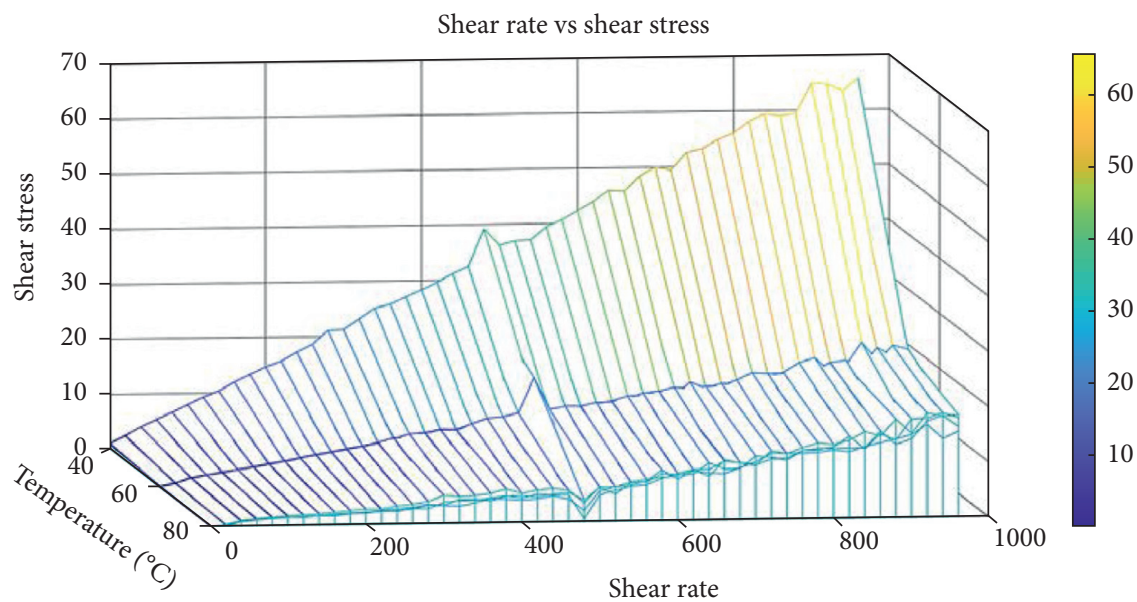

FIgURe 19: Plot of shear stress to shear rate.

TABLE 6: Correlation and regression analyses between shear stress and shear rate.

\begin{tabular}{|c|c|c|c|c|c|c|c|c|c|}
\hline \multirow{3}{*}{ Sample } & \multicolumn{3}{|c|}{$\begin{array}{l}\text { Correlation coefficient of shear } \\
\text { stress and shear rate }\end{array}$} & \multicolumn{6}{|c|}{ Regression coefficient of shear stress and shear rate } \\
\hline & \multirow{2}{*}{$40^{\circ} \mathrm{C}$} & \multirow{2}{*}{$60^{\circ} \mathrm{C}$} & \multirow{2}{*}{$80^{\circ} \mathrm{C}$} & \multicolumn{3}{|c|}{$R$ square } & \multicolumn{3}{|c|}{ Standard error } \\
\hline & & & & $40^{\circ} \mathrm{C}$ & $60^{\circ} \mathrm{C}$ & $80^{\circ} \mathrm{C}$ & $40^{\circ} \mathrm{C}$ & $60^{\circ} \mathrm{C}$ & $80^{\circ} \mathrm{C}$ \\
\hline 0 & 0.9869 & 0.9831 & 0.9126 & 0.97 & 0.96 & 0.83 & 2.52 & 1.12 & 2.02 \\
\hline 250 & 0.9928 & 0.9838 & 0.8636 & 0.985 & 0.9678 & 0.7458 & 2.5094 & 1.319 & 2.7884 \\
\hline 500 & 0.9950 & 0.9865 & 0.8664 & 0.989 & 0.973 & 0.7507 & 1.668 & 1.1532 & 3.5600 \\
\hline 750 & 0.9913 & 0.9553 & 0.8406 & 0.982 & 0.9125 & 0.7065 & 2.4258 & 2.2532 & 2.896 \\
\hline
\end{tabular}

TABLE 7: Correlation and regression analyses between viscosity and shear rate.

\begin{tabular}{|c|c|c|c|c|c|c|c|c|c|}
\hline \multirow{3}{*}{ Sample } & \multicolumn{3}{|c|}{$\begin{array}{l}\text { Correlation coefficient of shear stress } \\
\text { and shear rate }\end{array}$} & \multicolumn{6}{|c|}{ Regression coefficient of shear stress and shear rate } \\
\hline & \multirow{2}{*}{$40^{\circ} \mathrm{C}$} & \multirow{2}{*}{$60^{\circ} \mathrm{C}$} & \multirow{2}{*}{$80^{\circ} \mathrm{C}$} & \multicolumn{3}{|c|}{$R$ square } & \multicolumn{3}{|c|}{ Standard error } \\
\hline & & & & $40^{\circ} \mathrm{C}$ & $60^{\circ} \mathrm{C}$ & $80^{\circ} \mathrm{C}$ & $40^{\circ} \mathrm{C}$ & $60^{\circ} \mathrm{C}$ & $80^{\circ} \mathrm{C}$ \\
\hline 0 & 0.0888 & -0.2938 & 0.4909 & 0.0078 & 0.0863 & 0.2409 & 0.0027 & 0.0024 & 0.0031 \\
\hline 250 & 0.4385 & -0.0870 & 0.2434 & 0.1923 & 0.0075 & 0.0592 & 0.0031 & 0.0021 & 0.0034 \\
\hline 500 & -0.3223 & -0.3929 & 0.6089 & 0.1038 & 0.1543 & 0.3707 & 0.0020 & 0.0024 & 0.0038 \\
\hline 750 & 0.1845 & -0.2571 & 0.4150 & 0.0340 & 0.0660 & 0.1721 & 0.0029 & 0.0028 & 0.00326 \\
\hline
\end{tabular}




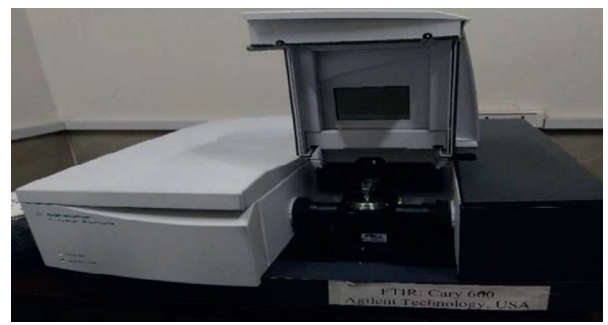

Figure 20: Experimental setup of FTIR.

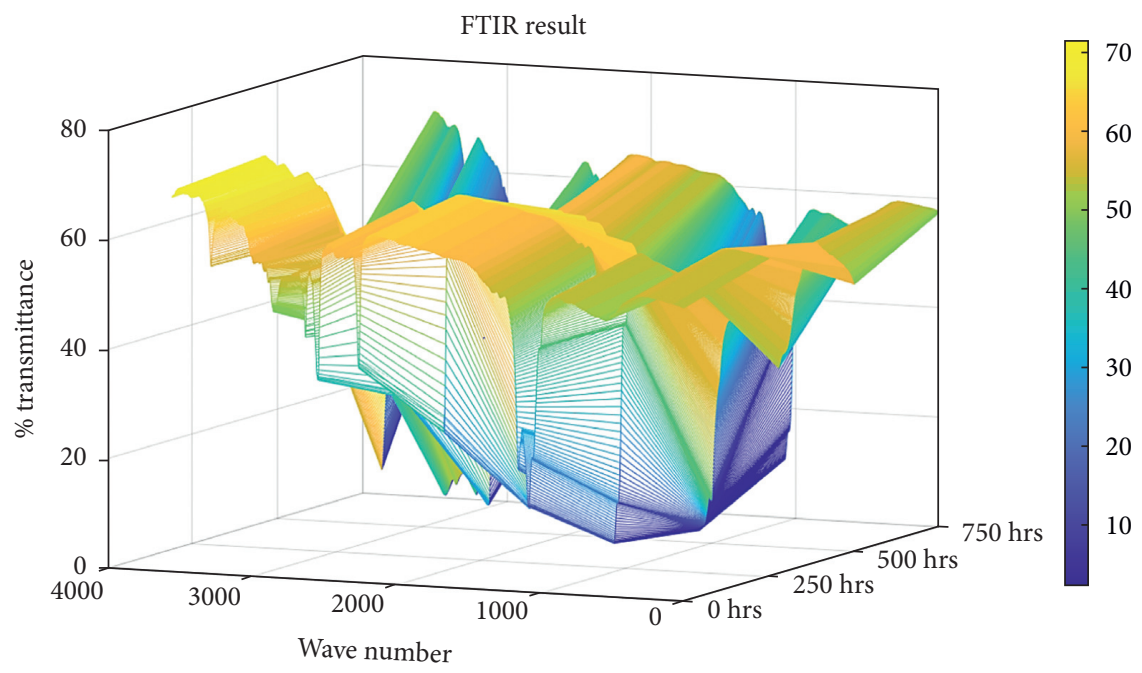

FIGURE 21: Combined FTIR spectra of all samples of HFDU 68 oil.

TABLE 8: Correlation and regression chart for wave number versus transmittance and absorbance.

\begin{tabular}{|c|c|c|c|c|c|c|}
\hline \multirow{3}{*}{ Sample } & \multicolumn{3}{|c|}{ Wave number vs transmittance } & \multicolumn{3}{|c|}{ Wave number vs absorbance } \\
\hline & \multirow{2}{*}{ Correlation coefficient } & \multicolumn{2}{|c|}{ Regression coefficient } & \multirow{2}{*}{ Correlation coefficient } & \multicolumn{2}{|c|}{ Regression coefficient } \\
\hline & & $R^{2}$ & Standard deviation & & $R^{2}$ & Standard deviation \\
\hline New & -0.5474 & 0.299 & 12.68 & 0.5689 & 0.323 & 0.163 \\
\hline 250 & -0.4375 & 0.191 & 18.26 & 0.49068 & 0.241 & 0.333 \\
\hline 500 & -0.265 & 0.0702 & 17.14 & 0.397 & 0.157 & 0.403 \\
\hline 750 & -0.2099 & 0.041 & 14.65 & 0.3171 & 0.1 & 0.230 \\
\hline
\end{tabular}

region of a hydroxyl group and single-bonded molecules. It can be seen that transmittance increases when the number of hours of oil usage increases, which is about $3500 \mathrm{~cm}^{-1}$. Antioxidants are mostly found in this region whose basic purpose is to prevent oil from oxidation, and these additives are deteriorating. This shows that ageing of oil is taking place, so oil condition has to be monitored at a certain interval for maintenance.

Region B: the triple bond region lies between wave number 2000 and $2500 \mathrm{~cm}^{-1}$; it mainly contains amines and hydroxyl group, which are triple-bonded compounds in the band range of $3100 \mathrm{~cm}^{-1}$ and $2700 \mathrm{~cm}^{-1}$. From the graph, it can be stated that increase in absorption signifies the condition of formation or increase in the composition of compounds in the oil.
Region $\mathrm{C}$ : double-bond region, $\mathrm{C}=\mathrm{O}, \mathrm{C}=\mathrm{C}, \mathrm{C}=\mathrm{N}$, and $\mathrm{N}=\mathrm{O}$, lies between wave number 1500 and $2000 \mathrm{~cm}^{-1}$. In this region, double-bonded compounds, such as alkenes, ketones, aldehydes, and amides, can be found in the band of $1800 \mathrm{~cm}^{-1}$. These are formed due to decreased transmittance as transmittance is lowest for $750 \mathrm{hrs}$ used oil. These results signify the oxidation of oil and formation of thicker oil; hence, the viscosity of the oil increases after a longer duration of usage.

Region D: at low wave number $650-1500 \mathrm{~cm}^{-1}$, the complex pattern of vibration can be observed. In this region, mostly all additives are found, which is also called fingerprint band. Compounds such as halogens, esters, carboxylic acids, and sulfur are found in a band range of $1500 \mathrm{~cm}^{-1}, 1200 \mathrm{~cm}^{-1}$, and $700 \mathrm{~cm}^{-1}$. As additives are made of sulfur elements and halogen elements, they are added to 
oil for antiwearing, antifriction, and anticorrosion. The mentioned activities are increased after long usage and as result of oxidized products.

\section{Results and Discussion}

The particular batch of hydraulic oil HFDU 68 supplied was of spurious quality. Continuously running in high temperatures caused its degradation expediently. Sludge formation and choking of hydraulic components accrued, which defunct the function of a hydraulic system. Oil samples were taken from machines running at elevated temperatures in chronological order of running, i.e., 0, 250, 500 , and 750 hrs. Four types of tests were conducted on the samples for confirming its quality. In the experimental study of viscosity, we found that the temperature drastically affects the oil viscosity. Dynamic viscosity of the new oil at $30^{\circ} \mathrm{C}$ was 89.508 milli-Pascal-sec, and at $90^{\circ} \mathrm{C}$, it became 10.310 milliPascal-sec. The initial viscosity of each sample showed increasing trends. The viscosity at every temperature of the successive sample was higher as compared to the previous sample because of the oxidation by-products and contamination of the oil, i.e., dynamic viscosity of new oil was 89.508, $250 \mathrm{hrs}$ used oil was 114.81, $500 \mathrm{hrs}$ used oil was 118.55 , and 750 hrs used oil was 127.73 . Kinematic viscosity also followed the same trend for all working hours. Correlation and regression analyses on experimental data also showed deviating trends with working hours at elevated temperatures. Total acid number test showed that the acid nature of the oil increased with the use of oil at elevated temperatures expediently, which was also validated with the correlation and regression analyses. OEM maximum allowable number of TAN is 1.1 , which reached in 500 -hrsused oil by 48 hrs of test program. Rheology experimental value showed shear thinning $(n<1)$ behaviour (pseudoplastic fluid) of non-Newtonian hydraulic oil till $60^{\circ} \mathrm{C}$, but between $60^{\circ} \mathrm{C}$ to $80^{\circ} \mathrm{C}$, it showed shear thickening $(n>1)$ behaviour (dilatants' fluid). Viscosity increases beyond this temperature. The increase in viscosity creates a problem in the flow in the hydraulic system, with the hydraulic system having many small diameter pipes. Thus, hydraulic gear pumps, priority valves, and many other components have a variety of losses. Operation of the LHD hydraulic system in the temperature range of $40^{\circ} \mathrm{C}$ to $60^{\circ} \mathrm{C}$ is suitable. FTIR has shown that some compounds have shown an increase in transmittance, whereas others have shown decreasing nature. From this, it can be concluded that degradation of oil is happening, and oil has to be monitored in intervals for proper checkups and replacements and the proper amount of top-up. FTIR analysis showed that oxidation takes place at elevated temperatures, and the by-products of oxidation are gummy and sticky compounds. The oil mainly consists of hydrocarbons, which react with oxygen during the oxidation process. Acids are formed and converted into a polymeric compound, which leads to a sludgy and gummy compound and varnish. Corrosion and wear increase in viscosity, and sludge and varnish are the consequences of oxidation. Acid formation may deteriorate the internal surface of the machine. Increase in temperature and time increases oxidation process by formation of oxidation products such as polymeric compounds and sludge. Sludge and varnish are imposing detrimental effects on the performance of the hydraulic components. Once it is deposited on the metal surface, it cannot dissolve easily, and varnish scaling can impede the performance of heat exchanger and eventually overheat is inevitable.

The basic reasons behind the formation of sludge in hydraulic oil HFDU 68 of LHD were diagnosed earlier to avoid the impact on the efficiency and performance of the machines. Machines downtime and consumption of hydraulic spares was increased by the usuage of the particular hydraulic batch. Thermal instability is the prime cause of oil degradation expeditiously. Organic acids formed rapidly while operating machines at elevated temperatures, and consequently, the sludge layering (semisolid material) was imposed on the internal surface of the hydraulic parts. Deformation of the basic structure of the oil into unwanted oxidised compounds at elevated temperatures due to the imbalance in the chemical composition while manufacturing is the reason for sludge formation.

\section{Conclusions and Recommendations}

The cynosure of this experimental study elucidates the rate of degradation of hydraulic oil accrued expeditiously when a machine is running continuously at elevated temperature range, i.e., $70^{\circ} \mathrm{C}$ to $80^{\circ} \mathrm{C}$, and formed varnish or sludge. High-temperature degradation is a common phenomenon with hydraulic oil, but standoff with sludge imposition is a cumbersome and disconcerting problem. Consequently, the sludge defunct the mechanical performance and increases power consumption along with egregious effects on the environment. Sludge has the potential against decomposition and remains in the environment for speculating eternally. Sludge management is a very cumbersome approach for oil companies and environment caretakers. Sludge conversion into biofuels is the best method of its disposal. It can be concluded from the experiments that degradation of hydraulic oil is accompanied by time and temperature. It is befitting to mitigate thermal degradation, so the inefficient hydraulic components are needed to be replaced without fail to reduce the heat load of the system. It is indispensable to operate the machines, in compliance with the recommended operating temperature range, and enhance the life of the hydraulic components and productivity. We consulted with the manufacturer of hydraulic oil HFDU68 , i.e., M/s Sun Oil, Kolkata, to improve the performance of oil to avoid damages of hydraulic components. They increased the percentage of BODPA, an antioxidant additive in the ester-based and fire-resistance mineral oil. High viscosity index fluids can be used to avoid hightemperature degradation repercussion. The novelty of this experiment is that the hydraulic oil HFDU 68 follow Specification IS-10532, Part-5, Organic Ester Type and IS: 7895-1975 (reaffirmed 2002) for fire resistance properties and have very high flash and fire point temperature range. Thermal degradation is a very contradictory affect, as per 
the specification. Therefore, the oil has been analyzed and shown to be unsuitable. Future work is to analyze the simulation of hydraulic system change in performance concerning the behavioural changes in the viscosity of hydraulic oil using Creo simulate 6.0 version software.

\section{Data Availability}

The data used to support the findings of this study are available from the corresponding author upon request.

\section{Conflicts of Interest}

The authors declare that they have no conflicts of interest.

\section{Acknowledgments}

The authors thank M/s Sun Oil, Kolkata, for their entire support and cooperation, providing test reports, and enhancing the performance of hydraulic oil by adding a percentage of an antioxidant for avoiding thermal cracking.

\section{References}

[1] I. O. Igwe, "The effects of temperature on the viscosity of vegetable oils in solution," Industrial Crops and Products, vol. 19, no. 2, pp. 185-190, 2004.

[2] A. Vasishth, P. Kuchhal, and G. Anand, "Study of rheological properties of industrial lubricants," Conference Papers in Science, vol. 2014, Article ID 324615, 5 pages, 2014.

[3] B.-R. Höhn and K. Michaelis, "Influence of oil temperature on gear failures," Tribology International, vol. 37, pp. 103-109, 2004.

[4] M. R. Kamal and A. Mutel, "Rheological properties of suspensions in Newtonian and non-Newtonian fluids," Journal of Polymer Engineering, vol. 5, no. 4, pp. 293-382, 1985.

[5] W. D. Phillips, "The high-temperature degradation of hydraulic oils and fluids," Journal of Synthetic Lubrication, vol. 23, no. 1, pp. 39-70, 2006.

[6] I. A. Gopang, H. Maha, A. S. Jatoi et al., "Characterization of the sludge deposits in crude oil storage tanks," Journal of Faculty of Engineering \& Technology, vol. 23, no. 1, pp. 57-64, 2016.

[7] M. Khan and A. Rasheed, "Slip velocity and temperature jump effects on molybdenum disulfide $\mathrm{MoS}_{2}$ and silicon oxide $\mathrm{SiO}_{2}$ hybrid nanofluid near irregular 3D surface," Alexandria Engineering Journal, vol. 60, no. 1, pp. 1689-1701, 2021.

[8] J. Oladejo, K. Shi, X. Luo et al., "A review of sludge-to-energy recovery methods,” Energies, vol. 12, no. 1, p. 60, 2019.

[9] K. Hui, J. Tang, H. Lu, B. Xi, C. Qu, and J. Li, "Status and prospect of oil recovery from oily sludge: a review," Arabian Journal of Chemistry, vol. 13, no. 8, 2020.

[10] C. Moragaspitiya, J. Rajapakse, G. J. Millar, and I. Ali, "Optimization of mesophilic anaerobic digestion of a conventional activated sludge plant for sustainability," Alexandria Engineering Journal, vol. 58, no. 3, pp. 977-987, 2019.

[11] S. Y. Lee, R. Sankaran, K. W. Chew et al., "Waste to bioenergy: a review on the recent conversion technologies," BMC Energy, vol. 1, pp. 1-22, 2019.

[12] O. A. Johnson and A. C. Affam, "Petroleum sludge treatment and disposal: a review," Environmental Engineering Research, vol. 24, no. 2, pp. 191-201, 2019.
[13] H. D. Al-Hamaiedh and O. N. Maaitah, "Treatment of oil polluted soil using electrochemical method," Alexandria Engineering Journal, vol. 50, no. 1, pp. 105-110, 2011.

[14] M. Hnilicová, M. Kučera, and J. Pavlů, "Analysis of hydraulic oil in handling lines Baljer \& Zembrod using the methods of tribotechnical diagnostics," Key Engineering Materials, vol. 669, 2016.

[15] J. A. Heredia-cancino, M. Ramezani, and M. E. ÁlvarezRamos, "Effect of degradation on tribological performance of engine lubricants at elevated temperatures," Tribology International, vol. 124, pp. 230-237, 2018.

[16] S. S. Kalligeros, "Predictive maintenance of hydraulic lifts through lubricating oil analysis," Machines, vol. 2, no. 1, pp. 1-12, 2014.

[17] A. Wolak, "Changes in lubricant properties of used synthetic oils based on the total acid number," Measurement and Control, vol. 51, pp. 65-72, 2018.

[18] S. Zzeyani, M. Mikou, J. Naja, and A. Elachhab, "Spectroscopic analysis of synthetic lubricating oil," Tribology International, vol. 114, pp. 27-32, 2017.

[19] E. Taborda, C. Franco, V. Alvarado, and F. Cortés, "A new model for describing the rheological behavior of heavy and extra heavy crude oils in the presence of nanoparticles," Energies, vol. 10, no. 12, p. 2064, 2017.

[20] M. Singh, G. S. Lathkar, and K. Basu, "Failure prevention of hydraulic system based on oil contamination," Journal of The Institution of Engineers (India): Series C, vol. 93, pp. 269-274, 2012.

[21] I. Stanciu, "Mathematical models describe rheological behavior PF rapeseed oils," International Journal of Sciences and Research, vol. 73, 2017.

[22] G. Xu, Y. Zhao, M. Li, Y. Hu, and L. Lin, "Effect of lubricant additives on the oxidation characteristics of diesel engine particulate matter," International Journal of Chemical Engineering, vol. 2020, Article ID 8867515, 9 pages, 2020.

[23] T. Yao, N. Zhang, J. Hu, X. Liao, Y. Shen, and Z. Gan, "Effect of temperature on the chemical composition and physicochemical properties of diester aviation lubrication oil," International Journal of Chemical Engineering, vol. 2020, Article ID 8829206, 15 pages, 2020.

[24] W. Ji, D. He, D. Wu, and M. K. Razi, "Research on the rheological properties of the plant oil pitch," International Journal of Chemical Engineering, vol. 2021, Article ID 5526113, 10 pages, 2021.

[25] I. Stanciu, "Correlation between dynamic viscosity and temperature for vegetable oil," Oriental Journal of Chemistry, vol. 36, no. 1, pp. 33-36, 2020.

[26] C. J. Seeton, "Viscosity-temperature correlation for liquids," Tribology Letters, vol. 22, 2006.

[27] L. Severa, M. Havlíček, and V. Kumbár, "Temperature dependent kinematic viscosity of different types of engine oils," Acta Universitatis Agriculturae et Silviculturae Mendelianae Brunensis, vol. 57, no. 4, pp. 95-102, 2014.

[28] M. Gülüm, F. K. Onay, and A. Bilgin, "Comparison of viscosity prediction capabilities of regression models and artificial neural networks," Energy, vol. 161, pp. 361-369, 2018.

[29] B. L. De Rivas, J.-L. Vivancos, J. Ordieres-Meré, and S. F. Capuz-Rizo, "Determination of the total acid number (TAN) of used mineral oils in aviation engines by FTIR using regression models," Chemometrics and Intelligent Laboratory Systems, vol. 160, pp. 32-39, 2017.

[30] L. Wei, H. Duan, Y. Jin et al., "Motor oil degradation during urban cycle road tests," Friction, vol. 9, pp. 1002-1011, 2021. 
[31] J. Kim, D. N. Kim, S. H. Lee, S.-H. Yoo, and S. Lee, "Correlation of fatty acid composition of vegetable oils with rheological behaviour and oil uptake," Food Chemistry, vol. 118, no. 2, pp. 398-402, 2010.

[32] J. A. Folayan, P. A L. Anawe, O. Abioye, and F. B. Elehinafe, "Selecting the most appropriate model for rheological characterization of synthetic based drilling mud," International Journal of Applied Engineering Research, vol. 12, no. 18, pp. 7614-7649, 2017.

[33] M. Adams, M. Romeo, and P. Rawson, "FTIR analysis and monitoring of synthetic aviation engine oils," Talanta, vol. 73, no. 4, pp. 629-634, 2007.

[34] C. V. Ossia, H. Kong, L. V. Markova, and N. K. Myshkin, "On the use of intrinsic fluorescence emission ratio in the characterization of hydraulic oil degradation," Tribology International, vol. 41, no. 2, pp. 103-110, 2008.

[35] M. A. Mohamed, J. Jaafar, A. F. Ismail, M. H. D. Othman, and M. A. Rahman, "Fourier transform infrared (FTIR) spectroscopy," Membrane Characterization, vol. 1, pp. 3-29, 2017. 